\title{
Recent developments in photocatalytic dye degradation upon irradiation with energy-efficient light emitting diodes
}

\author{
Wan-Kuen Jo ${ }^{a}$, Rajesh J. Tayade ${ }^{\mathrm{a}, \mathrm{b}, *}$ \\ a Department of Environmental Engineering, Kyungpook National University, Daegu 702-701, Korea \\ ${ }^{\mathrm{b}}$ Discipline of Inorganic Materials and Catalysis, CSIR-Central Salt and Marine Chemicals Research Institute, Council of Scientific and Industrial Research, \\ G B Marg, Bhavnagar-364002, Gujarat, India
}

\section{A R T I C L E I N F O}

Article history:

Received 15 June 2014

Accepted 24 July 2014

Published 20 November 2014

\section{Keywords:}

Light emitting diodes

Photocatalysis

Degradation

Dyes

Wastewater

\section{A B S T R A C T}

Light emitting diodes (LEDs) are gaining recognition as a convenient and energy-efficient light source for photocatalytic application. This review focuses on recent progress in the research and development of the degradation of dyes in water under LED light irradiation and provides a brief overview of photocatalysis, details of the LEDs commonly employed, a discussion of the advantages of LEDs over traditional ultraviolet sources and their application to photocatalytic dye degradation. We also discuss the experimental conditions used, the reported mechanisms of dye degradation and the various photocatalytic reactor designs and pay attention to the different types of LEDs used, and their power consumption. Based on a literature survey, the feasibility, benefits, limitations, and future prospects of LEDs for use in photocatalytic dye degradation are discussed in detail.

(C) 2014, Dalian Institute of Chemical Physics, Chinese Academy of Sciences. Published by Elsevier B.V. All rights reserved.

\section{Introduction}

An urgent need exists for solutions to current water pollution problems. The recent rapid growth of the industrial sector has led to environmental problems and to high levels of pollution worldwide. Additionally, there is an increase in demand for water in the industrial, agricultural, and domestic sectors, which generate large amounts of polluted wastewater. The general classes of compounds that occur in contaminated water are solvents, dyes, dioxins, dibenzofurans, pesticides, polychlorinated biphenyls (PCBs), chlorophenols, asbestos, arsenic, and heavy metals $[1,2]$. Among these, dyes are a serious contributor to pollution. Dyes are often difficult to decompose in water as they have composite molecular structures that cause them to be more stable toward light and resistant to biodegradation $[3,4]$. A considerable amount of dye-containing wastewater is generated in industries such as fabrics, leather, paper, food, cosmetics, agricultural research, pharmaceuticals, electroplating, and distillation. This causes damage to the environment as dyes are toxic to aquatic life [5,6]. Additionally, wastewater from the dye industry generally contains residual dyestuff, intermediary dyes, and non-reacted raw materials such as odorous amines, inorganic and organometallic salts, and waste solvents. These are found in different quantities and concentrations and are from different stages of the dye production process. Dye wastewater is generally considered to have an elevated chemical oxygen demand (COD) because of the presence of organic compounds, a high inorganic and organic dissolved substance content, inconsistent $\mathrm{pH}$, and low degradability by biological reagents. During the reduction of dyes and their intermediates the creation of strong carcinogenic or mutagenic compounds can occur, which has a detrimental impact on microorganisms and aquatic life [6]. Human consumption of water contaminated with these compounds can cause a variety of

\footnotetext{
* Corresponding author. Tel: +91-278-2567760.Ext.7180; Fax: +91-278-2567562; E-mail: rtayade@gmail.com DOI: 10.1016/S1872-2067(14)60205-9 | http://www.sciencedirect.com/science/journal/18722067 | Chin. J. Catal., Vol. 35, No. 11, November 2014
} 
adverse health effects such as wide-ranging immune suppression, breathing problems, central nervous system (CNS) disorders, behavioral problems, allergic reactions, tissue necrosis, and infections of the skin and eyes [7].

Dye molecules usually consist of two main components: chromophores and auxochromes. The chromophore absorbs a certain wavelength of light to produce the color. The auxochrome supplements the chromophore and helps the molecule dissolve in water, thus enhancing its color. Dyes show considerable structural variety and are classified by their chemical composition and the fabric type they are applied to. Dyes may also be classified on the basis of their solubility in various solvents. These include acidic, basic, direct, mordant, reactive and metal complex based dyes. Insoluble dyes include various types of azoic, sulfur, vat and disperse dyes. Furthermore, dyes may also be characterized based on the presence and type of azo and/or anthraquinone unit. More than 100000 commercial dyes are currently available on the market and throughout the world more than $7 \times 10^{5}$ tons of dyestuff are produced annually [8]. It is estimated that $10 \%-15 \%$ is lost in wastewater during manufacturing and application processes. This constitutes a huge environmental problem as these dyes are resistant to removal by irradiation with light or washing with water (or other chemicals) because of their robust chemical composition [9].

The primary methods of water treatment such as coagulation, flocculation, filtration, electro-flocculation, reverse osmosis, and adsorption do not degrade pollutants but instead decrease their levels by converting the pollutants from one form to another, thereby creating secondary pollution [10]. Because of the non-biodegradability and high solubility of dyes in water, activated sludge processes have been found to be ineffective for dye removal, and dyes are resistant to aerobic treatment. It has also been reported that the production of carcinogenic compounds such as aromatic amines can occur during the anaerobic treatment of dyes [11]. An alternative method used to degrade dyes in wastewater is oxidation [12]. The oxidation process uses oxidants such as molecular oxygen, ozone, or $\mathrm{H}_{2} \mathrm{O}_{2}$. However, a limitation of this process is the poor oxidation potentials of the oxidants and thus long treatment time is required. Therefore, there is a need to discover new materials with higher oxidation potentials to treat dye wastewater [13] The "advanced oxidation" process can also be used in which hydroxyl radical species are generated to degrade the dyes in wastewater [14]. This technique requires a high energy light irradiation source (usually an ultraviolet (UV) light source) and an oxidant to generate hydroxyl radicals. Typical systems employed to date are UV/hydrogen peroxide, UV/ozone, $\mathrm{UV} /$ Fenton reagent and $\mathrm{UV} / \mathrm{TiO}_{2}$ [15]. These photocatalytic degradations have been carried out in the presence of natural sunlight or a mercury vapor lamp [16,17]. However, energy-efficient light emitting diodes (LEDs) have recently been used as an alternative light source for the photocatalytic degradation of various pollutants present in water $[18,19]$ and in air [20,21].

LEDs are emerging as a new irradiation source and many researchers are studying the photocatalytic activity of synthe- sized photocatalysts under LED irradiation and exploring photocatalytic reactor designs. To date, only two review articles have been published that focus on the use of LEDs in photocatalysis and in plant tissue culture [22,23]. This review mainly focuses on recent developments in photocatalytic dye degradation and the mechanisms by which it occurs. We also briefly discuss the basic principles of photocatalysis, the details of some of the LEDs used, the advantages of LEDs over conventional UV light sources, the development of photocatalytic degradation reactors using LEDs, and the future prospects of LEDs in this field.

\section{Basic principles of photocatalysis}

Heterogeneous semiconductor photocatalysis has been widely explored over the last few decades for various environmental application. These studies typically investigated the use of different sources of light irradiation and the nature of the solid semiconductor on the degradation of liquid and gas-phase pollutants [24]. Photocatalysis can be defined as a change in the rate of chemical reactions or their initiation under light in the presence of a photocatalyst. Photocatalysts are a class of compound that produce electron-hole pairs upon the absorption of light quanta and they induce chemical transformations in reaction substrates that come into contact with them. They then undergo regeneration to their original electronic composition. Many semiconductors have been synthesized and studied as photocatalysts including zinc oxide ( $\mathrm{ZnO}, 3.2 \mathrm{eV})$, titanium dioxide $\left(\mathrm{TiO}_{2}, 3.2 \mathrm{eV}\right)$, strontium titanate $\left(\mathrm{SrTiO}_{3}, 3.4 \mathrm{eV}\right)$, iron oxide $\left(\mathrm{Fe}_{2} \mathrm{O}_{3}, 2.2 \mathrm{eV}\right)$, cadmium sulfide ( $\mathrm{CdS}, 2.5 \mathrm{eV}$ ), tungsten trioxide $\left(\mathrm{WO}_{3}, 2.8 \mathrm{eV}\right)$, zinc sulfide $(\mathrm{ZnS}, 3.6 \mathrm{eV})$, ilmenite $\left(\mathrm{FeTiO}_{3}, 2.8 \mathrm{eV}\right)$, zirconium dioxide $\left(\mathrm{ZrO}_{2}, 5.0 \mathrm{eV}\right)$, vanadium oxide $\left(\mathrm{V}_{2} \mathrm{O}_{5}, 2.8 \mathrm{eV}\right)$, niobium pentoxide $\left(\mathrm{Nb}_{2} \mathrm{O}_{5}, 3.4 \mathrm{eV}\right)$, and tin oxide $\left(\mathrm{SnO}_{2}, 3.5 \mathrm{eV}\right)$. Of these, $\mathrm{TiO}_{2}$ has been found most suitable for general environmental remediation [25-27].

$\mathrm{TiO}_{2}$ is widely used as a photocatalyst because it is inexpensive, stable in biological and chemical environments, and is stable to photocorrosion. $\mathrm{TiO}_{2}$ has a unique property in that natural (solar) UV light generates electron-hole pairs for redox reactions. This is because $\mathrm{TiO}_{2}$ has a suitably sized bandgap between its valence band $(\mathrm{VB},+3.0 \mathrm{eV})$ and conduction band $(\mathrm{CB},-0.2 \mathrm{eV}$ ) resulting in a bandgap of $3.2 \mathrm{eV}$ allowing energy of near-UV light with a wavelength greater than $387 \mathrm{~nm}$ to generate electron-hole pairs. Although $\mathrm{ZnO}$ has characteristics similar to $\mathrm{TiO}_{2}$ and appears to present a suitable alternative, it dissolves in solutions at low $\mathrm{pH}$ and cannot be used for the photocatalytic degradation of pollutants [28].

When sufficiently energetic photons strike a semiconductor, an electron may be excited out of its energy level from the valance band and thus leave a hole. This phenomenon is termed electron-hole pair generation. These electron-hole pairs are continuously generated in the presence of a constant energy source. Unselective degradation occurs at the surface of the photocatalyst via similar and successive redox reactions in which the oxidized organic compounds are the end products. A schematic presentation of the mechanism of the generation of oxidative species from a photocatalytic study is shown in Fig. 1. 


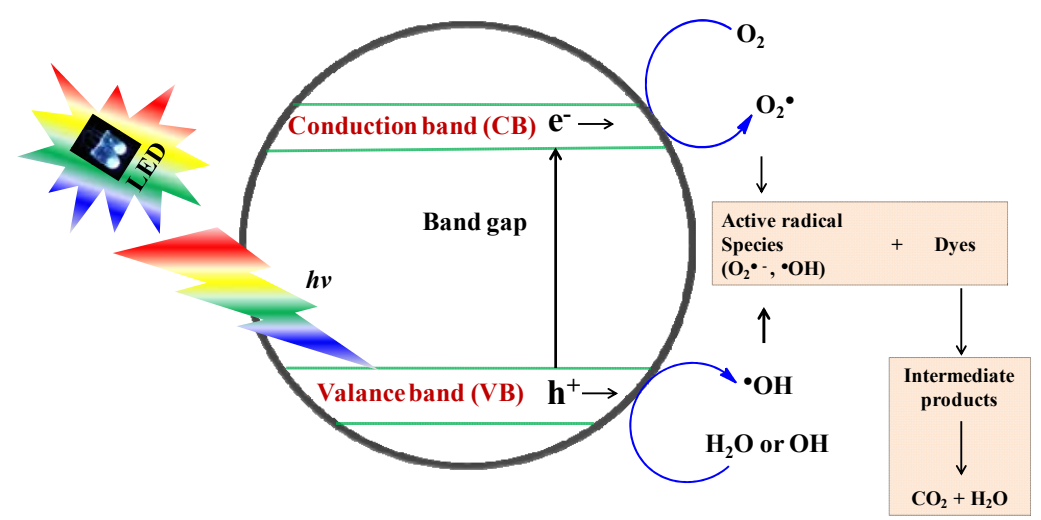

Fig. 1. The mechanism of photocatalysis.

The following series of reactions shows the generation of

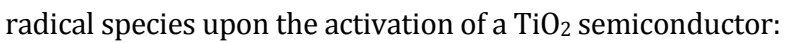

$$
\begin{gathered}
\mathrm{TiO}_{2}+h v \rightarrow \mathrm{TiO}_{2}\left(\mathrm{e}^{-}{ }_{(\mathrm{CB})}+\mathrm{TiO}_{2} \mathrm{~h}^{+}(\mathrm{VB})\right) \\
\mathrm{h}^{+}(\mathrm{VB})+\mathrm{H}_{2} \mathrm{O} \text { or } \mathrm{OH} \rightarrow \mathrm{H}^{+}+\cdot-\mathrm{OH} \\
\mathrm{e}^{-}(\mathrm{CB})+\mathrm{O}_{2} \rightarrow \mathrm{O}_{2}{ }^{--} \\
\mathrm{O}_{2}{ }^{--}+\mathrm{H}^{+} \rightarrow \mathrm{HO}_{2} \cdot \\
2 \mathrm{HO}_{2}+2 \mathrm{H}^{+} \rightarrow \mathrm{H}_{2} \mathrm{O}_{2}+2 \cdot \mathrm{OH} \\
2 \mathrm{HO}^{\bullet} \rightarrow \mathrm{O}_{2}+\mathrm{H}_{2} \mathrm{O}_{2} \\
\mathrm{H}_{2} \mathrm{O}_{2}+\mathrm{e}^{-}(\mathrm{CB}) \rightarrow \mathrm{OH}^{-}+\cdot \cdot \mathrm{OH}
\end{gathered}
$$

The radical species that are most active during oxidation are $\mathrm{O}_{2} \bullet-, \mathrm{HO}_{2} \bullet$ and $\bullet \mathrm{OH}$. Employing photocatalysis for complete oxidation (as opposed to partial oxidation) to provide an alternative to the conventional removal of pollutants from wastewater has attracted growing interest among researchers $[29,30]$.

\section{History and fundamentals of LEDs}

The first infrared LED was invented and patented by Robert Biard and Gary Pittman for Texas instruments in 1961. In 1962, Nick Hilonyack invented the red visible LED using gallium arsenide phosphide as a substrate for the diode. The first yellow LED was invented by M. George in 1972. These LEDs were bright and were mainly used as indicators in equipment. The commercial production of LEDs began in the 1970s. Further advances in LED materials technology resulted in the manufacture of units capable of a higher amount of light output.

Over the past few decades, continuous and rapid technological advances have occurred in the development of solid-state technology. These advances include the development of lower cost and environmentally friendly LEDs. The first LEDs were only capable of dim red output, and green LEDs were developed shortly after. However, over the past 15 years the development of solid-state technology has provided more powerful LEDs in a wide spectrum of colors. In the early 1990s, the development of the first blue LED provided an opportunity to create practically any color of light, making it technically possible to generate white light from semiconductor devices. The economic mass-production of white LEDs is the current target of researchers and manufacturers in this field, and this is likely to end our current dependence on inefficient incandescent lamps.

LEDs can emit light at different wavelengths (infrared, visi- ble, or UV) based on the composition and condition of the semiconducting materials. LEDs comprise a solid-state technology based entirely on p-n junction devices that are developed using semiconductors such as gallium arsenide (GaAs), gallium arsenide phosphide (GaAsP), gallium phosphide (GaP), or indium gallium nitride (InGaN). LEDs are far more efficient than incandescent lamps at converting electricity into visible light while being robust and small. Furthermore, they can be used for up to $100000 \mathrm{~h}$, which is around 100 times longer than incandescent lamps. LEDs provide monochromatic light, and can be used in application where there is a need for high brightness and single-color irradiation. Recently, LEDs have been found to be an alternative for traditional UV irradiation, and they have been used in various application including UV curing, disinfection, sensors and photocatalytic application [31-41].

LEDs are considered capable of generating cold light because of their low operating temperature. Indeed, $5 \mathrm{~mm}$ LEDs are usually only $10-25{ }^{\circ} \mathrm{C}$ warmer than the ambient temperature during operation whereas incandescent bulbs can be several hundred degrees warmer under similar conditions. The material used to make a LED dictates the energy of the photons that leave the diode. Each wavelength of light has a certain amount of energy associated with the photons being carried. The closer the wavelengths are to UV and shorter wavelengths, the more energy they contain. The highest amount of light generated by most LEDs is around its peak wavelength. LEDs may produce light of different wavelengths including infrared, UV, and visible light.

A basic LED consists of a "p and n" type semiconductor junction. Upon the application of potential across the junction, current flow injects charge carriers across the junction and the emission of light takes place. The p-n junctions in LEDs normally consist of a mixture of Group III and Group V elements like gallium arsenide, gallium arsenide phosphide, and gallium phosphide. The basic element of a LED is a semiconductor integrated circuit, which is joined to two electrical wires. This unit is mounted in a reflector cup supported by a lead frame and it is fixed in a solid epoxy lens.

In this $\mathrm{p}-\mathrm{n}$ junction, the $\mathrm{p}$-type region is dominated by positive charges and the n-type region is dominated by negative charges. After the application of sufficient voltage across the LED's electrical contacts, current flows and electrons move across the junction from the n-type semiconductor region into 
the p-type semiconductor region. The negatively-charged electrons then combine with positive charges. Each combination of charges at the junction is related to a drop in energy level and a quantum of electromagnetic energy is liberated in the form of light. The frequency and, therefore, the apparent color of the emitted photons is characteristic of the semiconductor material. Consequently, different color LEDs can be obtained by changing the semiconductor composition of the chip used.

\section{LEDs vs. conventional UV irradiation sources}

The disadvantages associated with conventional mercury UV lamps are that they are delicate, contain mercury (which is hazardous and creates disposal problems after use), have a short working life-span of only 100-1000 h, and they are prone to gas leakage. Additionally, lamp-blast is possible in medium and high pressure lamps. Furthermore, the operating temperature of medium/high pressure UV lamps is in the range of 600 to $900{ }^{\circ} \mathrm{C}$ and, therefore, they need to be cooled during the reaction, which results in increased energy consumption. However, LEDs (both UV and visible) are robust, safe, compact, cool, non-toxic, inexpensive, environmentally friendly and have a long life-span of around $100000 \mathrm{~h}$. Moreover, LEDs can emit light at different wavelengths based on the composition and condition of the semiconducting materials [31]

\section{Application of LEDs to the photocatalytic degradation of dyes}

The first article on the use of UV-LEDs was published in 2005 by Chen et al. [32], who explored the use of UV-LEDs (peak wavelength: $375 \mathrm{~nm}$; spectrum half width: $12 \mathrm{~nm}$; optical power output: $1 \mathrm{~mW}$ ) as an alternative source of light for the oxidation of perchloroethylene (PCE). Since then, there have been a number of application of UV and visible LEDs to the photocatalytic degradation of aqueous dye pollutants such as methylene blue (MB), rhodamine $B(\mathrm{RhB})$, malachite green (MG), reactive red 22 (RR-22), methyl orange (MO), congo red (CR), and reactive black 5 (RB-5). Table 1 lists dyes that have been degraded using different LEDs with their wavelength, type, power, and the photocatalysts used for the degradation [31-57]. Fig. 2 shows the chemical structure of the synthetic

Table 1

List of LEDs used for the removal of dyes.

\begin{tabular}{|c|c|c|c|c|c|c|}
\hline Dye & $\begin{array}{l}\text { LED wavelength } \\
(\mathrm{nm})\end{array}$ & LED type & LEDs number and its power & Catalyst & $\begin{array}{l}\text { Dye degradation } \\
(\%)\end{array}$ & Ref. \\
\hline MB & $255,310,365$ & Chip & $\begin{array}{c}\text { 7, 14, } 21(0.031,0.065,0.099 \\
\left.\mathrm{m} / \mathrm{Wcm}^{2}\right)\end{array}$ & $\mathrm{TiO}_{2}$ (P25 Degussa) & 90 & [33] \\
\hline MB, PR, MR & 405 & Bulb & One, $24 \mathrm{~W}$ & CdS microsphere & 100 & [34] \\
\hline $\mathrm{MB}, \mathrm{PR}, \mathrm{MR}$ & 450 & Bulb & One, $17.5 \mathrm{~W}$ & CdS microsphere & 100 & [34] \\
\hline MB & 376 & Chip & $\begin{array}{c}6 \times 21 \text { (four side), power not men- } \\
\text { tioned }\end{array}$ & $\mathrm{TiO}_{2}(\mathrm{P} 25$ Degussa) & 91 & [35] \\
\hline MB & 365 & Bulb & $600 \mathrm{~mW} / \mathrm{Cm}^{2}$ & $\mathrm{ZnO}$ and $\mathrm{TiO}_{2}$ & 60 & {$[36]$} \\
\hline MB & $390-410$ & Bulb, $d 5 \mathrm{~mm}$ & $5,10-12 \mathrm{~mW}$ for each LED & $\mathrm{TiO}_{2}(\mathrm{P} 25$ Degussa) and & 100 & {$[31,37]$} \\
\hline MB, MO & $400-800$ & LED strip & $30,6 \mathrm{~W}$ & N-doped $\mathrm{TiO}_{2}$ & 100 & [38] \\
\hline MB, MG, RhB & $390-410$ & Bulb, $d 5 \mathrm{~mm}$ & $15,10-12 \mathrm{~mW}$ for each LED & $\mathrm{TiO}_{2}$ & $61,99,62$ & [39] \\
\hline MB & 540 & Bulb & $5 \times 20$ LED arrays, $400 \mu \mathrm{W} / \mathrm{cm}^{2}$ & $\mathrm{TiO}_{2}$ (P25 Degussa) & 91 & [35] \\
\hline MB, MO & 370 & Bulb & $250 \mathrm{~mW}$ & $\mathrm{TiO}_{2}(\mathrm{P} 25$ Degussa) & 100 & [40] \\
\hline $\mathrm{MB}$ & 450 & Bulb & $5 \times 20$ LED array, $6 \mathrm{~W}$ & $\mathrm{Ag} / \mathrm{AgBr}$ heterostructure & 95 & [41] \\
\hline MB & 475 & Bulb & $6 \times 2$, not mentioned & $\begin{array}{c}\mathrm{TiO}_{2}(\mathrm{P} 25 \text { Degussa }) \text { and Nickel } \\
\text { modified } \mathrm{TiO}_{2}\end{array}$ & Not mentioned & {$[42]$} \\
\hline $\mathrm{MB}, \mathrm{PR}, \mathrm{MR}$ & 475 & Bulb & $1,3 \mathrm{~W}$ & CdS nanostructures & 100 & [43] \\
\hline $\mathrm{MB}$ & 410 & Bulb & $5 \times 2,7 \mathrm{~W}$ & $\mathrm{AgBr} / \mathrm{ZnO}$ composite & 92 & [44] \\
\hline MB & 375 & Bulb & $10 \times 10$ & $\begin{array}{l}\text { Graphene oxide oxide modified } \\
\text { ZnO nanorods }\end{array}$ & 98 & [45] \\
\hline BR & 240 & Bulb & $6,1 \mathrm{~W}$ & $\begin{array}{l}\text { Peroxydisulfate } \\
\left(\mathrm{S}_{2} \mathrm{O}_{8}{ }^{2-}\right)\end{array}$ & 90 & {$[46]$} \\
\hline CR & $390-410$ & Bulb, $d 5 \mathrm{~mm}$ & $4,10-12 \mathrm{~mW}$ for each LED & Titanium nanotube array & 100 & [55] \\
\hline DR-23 & 385 & Blub & $6,3 \mathrm{~W}$ & Nano- $\mathrm{TiO}_{2} / \mathrm{S}_{2} \mathrm{O}_{8}{ }^{2-}$ & 90 & [48] \\
\hline RR-22 & 405 & Bulb & $4 \times 20$, not given & $\begin{array}{c}\text { Degussa P-25 } \mathrm{TiO}_{2} \text { coated quartz } \\
\text { plate }\end{array}$ & 95 & [49] \\
\hline MO & 375 & Bulb & 15, $2 \mathrm{~mW}$ for each LED & $\begin{array}{c}\mathrm{P}-25 \mathrm{TiO}_{2} \text { and } \mathrm{P}-25 \mathrm{TiO}_{2} \text { coated } \\
\text { glass wafer }\end{array}$ & 100 & {$[50]$} \\
\hline MO & 360 & Bulb, $d 5 \mathrm{~mm}$ & $6 \times 6$ strip, $435 \mu \mathrm{W}$ & Degussa P-25 $\mathrm{TiO}_{2}$ & 89 & [51] \\
\hline $\mathrm{AO}-7$ & $390-395$ & Bulb, $d 5 \mathrm{~mm}$ & $2 \times 11,3-35 \mathrm{~W}$ & $\begin{array}{l}\text { Glucose oxidase / } \\
\mathrm{TiO}_{2} / \text { polyurethane }\end{array}$ & 99 & {$[54]$} \\
\hline MB & 463 & Bulb & $1,10 \mathrm{~W}$ & Nitrogen modified $\mathrm{TiO}_{2}$ & 67 & [53] \\
\hline RB-5 & $240-355$ & Bulb & $6,1 \mathrm{~W}$ each & Peroxydisulfate $\left(\mathrm{S}_{2} \mathrm{O}_{8}{ }^{2-}\right)$ & 99 & {$[54]$} \\
\hline RhB, MO & $450-475$ & BULB & $3,1 \mathrm{~W}$ & Polymer modified ZnO & 100,40 & [58] \\
\hline RhB & $390-410$ & Bulb, $d 5 \mathrm{~mm}$ & $5,10-12 \mathrm{~mW}$ for each LED & $\mathrm{TiO}_{2}$ (P25 Degussa) & 100 & {$[37,55]$} \\
\hline $\mathrm{RhB}$ & 465 & Bulb & $1,3 \mathrm{~W}$ & $\mathrm{Bi}_{2} \mathrm{MoO}_{6}$ & 99 & {$[56]$} \\
\hline $\mathrm{RhB}$ & 443 & Bulb & $1,4 \mathrm{~W}$ & $\mathrm{Sb}_{2} \mathrm{O}_{3} / \mathrm{WO}_{3}$ & 45 & [57] \\
\hline
\end{tabular}


<smiles>CN(C)c1ccc2nc3ccc(N(C)C)cc3c(Cl)c2c1</smiles><smiles>COc1ccc(OC(=O)CCON)cc1N=Nc1ccc2c(O)cccc2c1O</smiles>

Reactive red<smiles>CN(C)c1ccc(C(=C2C=CC(=[N+](C)C)C=C2)c2ccccc2)cc1</smiles>

Malachite green

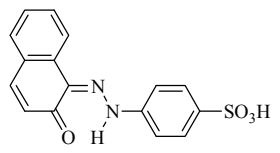

Acid orange 7<smiles>COc1ccc(Nc2ccc(C(c3ccc(Nc4ccc([N+](=O)[O-])cc4)cc3)c3ccc(Nc4ccc([N+](=O)[O-])cc4)cc3)cc2)cc1</smiles>

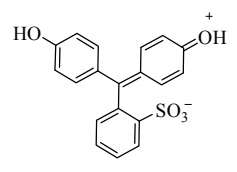

Phenol red<smiles>CN(C)c1ccc(NNc2ccccc2C(=O)O)cc1</smiles>

Methyl red

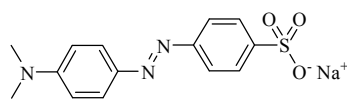

Methyl orange

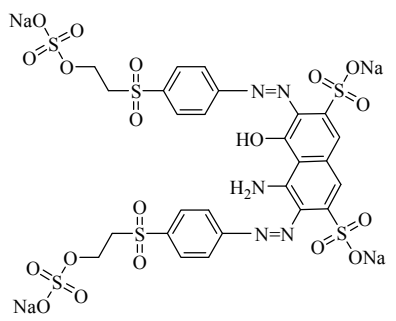

Reactive black 5<smiles>CCN(CC)c1ccc2c(c1)Oc1cc(N(CC)CC)ccc1-c1ccccc1C2=O</smiles>

Rhodamine B

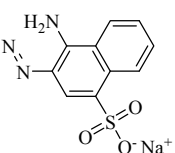

(1)
Basic Red 4

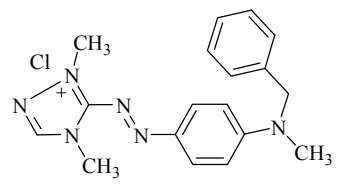

(c)

Direct red 23

Fig. 2. Chemical structure of the synthetic dyes degraded by LED irradiation.

dyes studied in photocatalytic degradation experiments using LED irradiation.

Wang et al. [49] carried out a reactive red 22 dye photocatalytic degradation study under irradiation by UV-LEDs and this is one of the dyes listed in Fig. 2. A large number of studies into the degradation of dyes using LEDs have been conducted. Here, we summarize the work conducted on the degradation of various dyes under irradiation by UV and visible LEDs. The properties of the dyes covered in this review are given in Table 2 . The proposed general mechanism of photocatalytic dye degradation using various photocatalysts upon irradiation by LEDs is given in Fig. 3.

Wang et al. [49] demonstrated that UV-LEDs can be used as a UV light irradiation source for the photocatalytic mineralization of reactive red 22. Specifically, they investigated the pho- tocatalytic degradation of RR-22 in aqueous solution by UV-LEDs with $\mathrm{TiO}_{2}$ as a photocatalyst. They studied this photocatalytic degradation using a rectangular planar fixed-film reactor in recirculation mode and investigated various conditions including the initial dye concentration (ranging from 10 to $100 \mathrm{mg} / \mathrm{L})$, periodic illumination $\left(0.36-0.90 \mathrm{~mW} / \mathrm{cm}^{2}\right)$, light intensity variation in the range of $1.0-7.3 \mathrm{~mW} / \mathrm{cm}^{2}$, and different $\mathrm{TiO}_{2}$ coating arrangements. They concluded that the decomposition of reactive red 22 in aqueous solutions via a $\mathrm{TiO}_{2}$ photocatalyzed process using UV-LED irradiation was technically feasible under adequate experimental conditions.

Methylene blue has often been used as a model pollutant in water, and many researchers have studied the degradation and decolorization of methylene blue dye to determine the photocatalytic activity of standard and synthesized materials under

Table 2

Properties of selected dyes.

\begin{tabular}{lcccccc}
\hline Sr. No. & Dye name & Molecular mass (amu) & Chemical formula & Class & Absorption, $\lambda_{\max }(\mathrm{nm})$ & Solubility in water \\
\hline 1 & Methylene blue & 319.86 & $\mathrm{C}_{16} \mathrm{H}_{18} \mathrm{ClN}_{3} \mathrm{~S}$ & thiazin & 644 & soluble \\
2 & Malachite green & 927.02 & $\mathrm{C}_{52} \mathrm{H}_{54} \mathrm{~N}_{4} \mathrm{O}_{12}$ & triarylmethane & 628 & very soluble \\
3 & Phenol red & 354.38 & $\mathrm{C} 19 \mathrm{H}_{1405 \mathrm{~S}}$ & triphenylmetha-ne & 558 & soluble \\
4 & Methyl orange & 327.32 & $\mathrm{C}_{14} \mathrm{H}_{14} \mathrm{~N}_{3} \mathrm{NaO}_{3} \mathrm{~S}$ & azo & 462 & soluble in hot water \\
5 & Reactive red 22 & 590.51 & $\mathrm{C}_{19} \mathrm{H}_{16} \mathrm{~N}_{2} \mathrm{Na}_{2} \mathrm{O}_{11} \mathrm{~S}_{3}$ & azo & 511 & soluble \\
6 & Congo red & 696.665 & $\mathrm{C}_{32} \mathrm{H}_{22} \mathrm{~N}_{6} \mathrm{Na}_{2} \mathrm{O}_{6} \mathrm{~S}_{2}$ & azo & 500 & soluble \\
7 & Reactive black 5 & 991.82 & $\mathrm{C}_{26} \mathrm{H}_{21} \mathrm{~N}_{5} \mathrm{Na}_{4} \mathrm{O}_{19} \mathrm{~S}_{6}$ & azo & 597 & soluble \\
8 & Basic red 46 & 357.5 & $\mathrm{C}_{18} \mathrm{~N}_{6} \mathrm{H}_{21} \mathrm{~N}_{6}$ & mono Azo & 531 & soluble \\
9 & Acid organge 7 & 350.3 & $\mathrm{C}_{16} \mathrm{H}_{11} \mathrm{~N}_{2} \mathrm{NaSO}_{4}$ & mono Azo & $307-313$ & soluble \\
10 & Direct Red 23 & 813.72 & $\mathrm{C}_{35} \mathrm{H}_{25} \mathrm{~N}_{7} \mathrm{Na}_{2} \mathrm{O}_{10} \mathrm{~S}_{2}$ & double Azo & 507 & soluble \\
\hline
\end{tabular}


1786

Wan-Kuen Jo et al. / Chinese Journal of Catalysis 35 (2014) 1781-1792

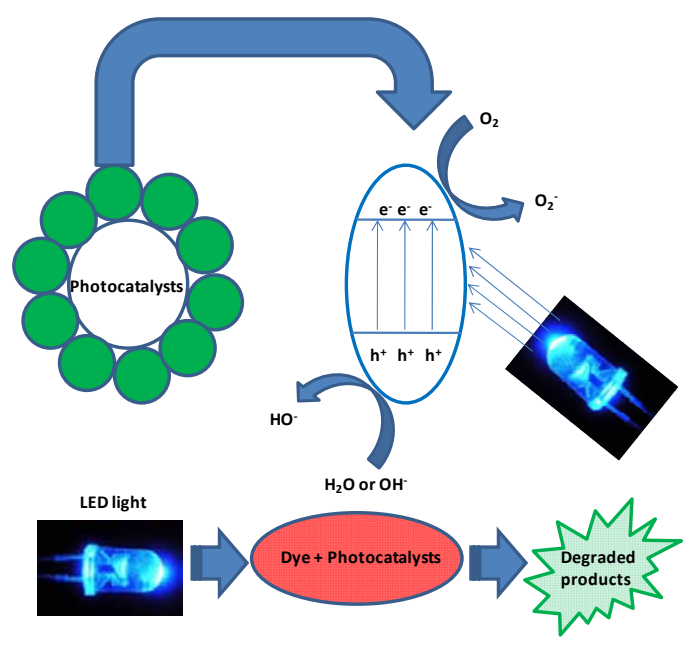

Fig. 3. General mechanism of dye degradation upon LED irradiation.

UV-LED irradiation [31,33-45].

In 2009, Tayade et al. [31,37,47] demonstrated a simple photocatalytic set up using five UV-LEDs for the photocatalytic decomposition and mineralization of methylene blue and Rho- damine B. In this set-up, the photocatalyst (P25 Degussa) was suspended in a particular dye solution and then irradiated with UV-LEDs. They also investigated the effects of operational parameters such as the mass of the photocatalyst, the dye concentration, the $\mathrm{pH}$, and the addition of hydrogen peroxide on the decolonization and mineralization of methylene blue to identify the most favorable conditions for remediation. Furthermore, they demonstrated the possibility of the complete degradation of methylene blue dye $\left(3.12 \times 10^{-5} \mathrm{~mol} / \mathrm{L}\right)$ and Rhodamine B dye $\left(2.08 \times 10^{-5} \mathrm{~mol} / \mathrm{L}\right)$ based on a chemical doxygen demand (COD) analysis and reported that the UV-LED and $\mathrm{TiO}_{2}$ process could successfully degrade the methylene blue dye under optimal conditions. Additionally, they reported that the optimum conditions for Rhodamine B dye photocatalytic degradation in terms of catalyst content, dye concentration and $\mathrm{pH}$ were $1.6 \mathrm{~g} / \mathrm{L}, 6.26 \times 10^{-5} \mathrm{~mol} / \mathrm{L}$, and 3.05 , respectively, and in the case of methylene blue they were $1.2 \mathrm{~g} / \mathrm{L}, 3.12 \times 10^{-5}$ $\mathrm{mol} / \mathrm{L}$, and 8.84 , respectively. They also proposed a mechanism for the photocatalytic decomposition of Rhodamine B that was in agreement with that of the photocatalytic degradation of Rhodamine B dye using conventional UV sources (Scheme 1).

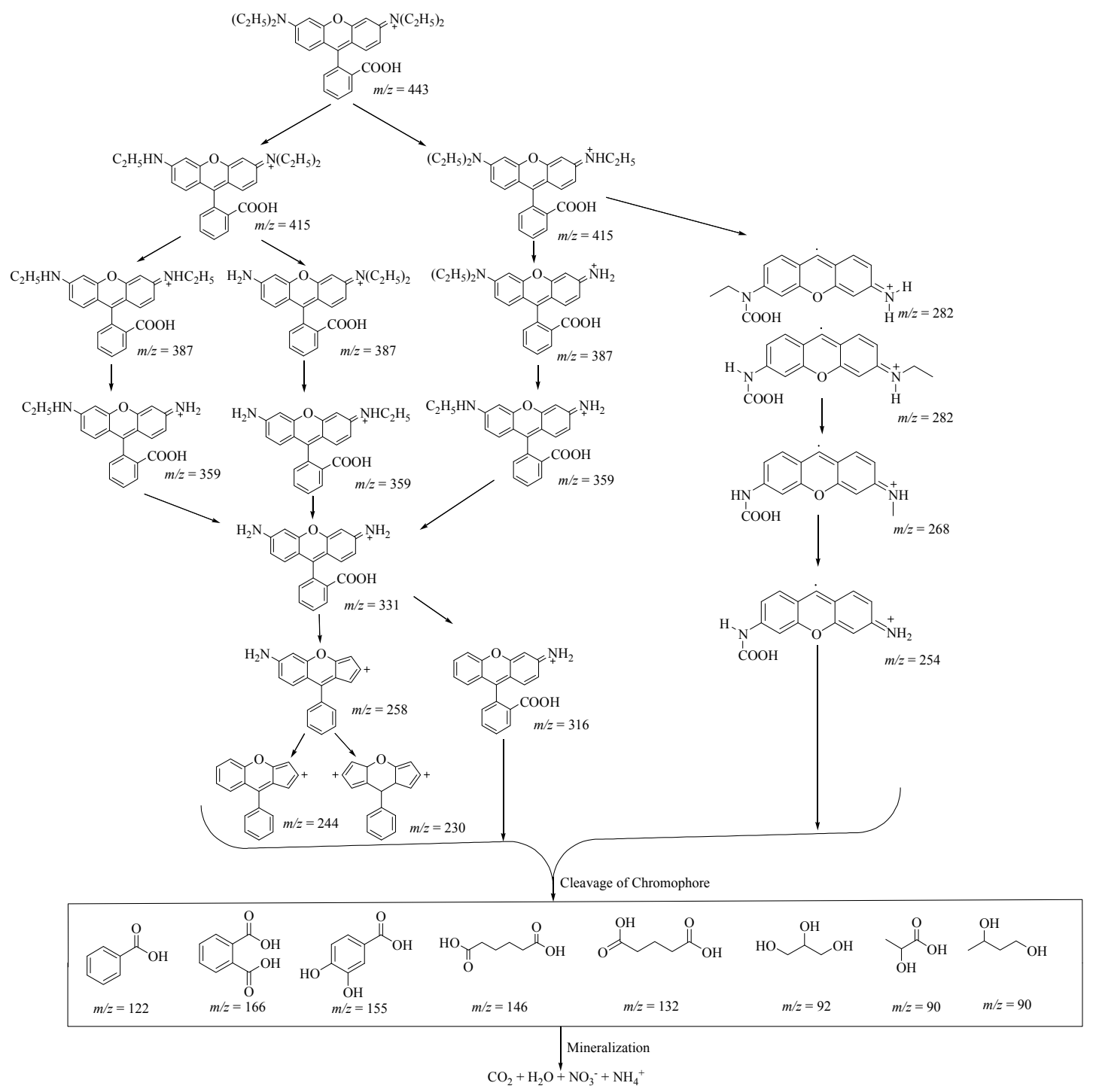

Scheme 1. Mechanism of the photocatalytic mineralization of Rhodamine B. 
Specifically, they reported that the mineralization of Rhodamine B occurs via a N-de-ethylation process with the N-de-ethylated product being oxidized to adipic acid, 2-hydroxypropanoic acid, propane-1,2,3-triol and butane-1,3-diol. The formed acids are then mineralized to $\mathrm{CO}_{2}, \mathrm{H}_{2} \mathrm{O}, \mathrm{NO}_{3}{ }^{-}$, and $\mathrm{NH}_{4}{ }^{+}[31,47]$.

Similarly, Joonwichien et al. [36] studied the photocatalytic degradation of methylene blue upon UV-LED exposure using $\mathrm{ZnO}$ and $\mathrm{TiO}_{2}$ particles with a magnetic field surrounding the reactor. The bandgaps for the $\mathrm{ZnO}$ and $\mathrm{TiO}_{2}$ particles were 3.37 and $3.2 \mathrm{eV}$, respectively. They irradiated a mixture of MB solution and a photocatalyst that was contained in a sample holder composed of quartz using a UV-LED lamp (OMRON, ZUV-L8V, Kyoto, Japan) at a wavelength of $365 \mathrm{~nm}$ and an intensity of $600 \mathrm{~mW} / \mathrm{cm}^{2}$. In this system, light was provided from the bottom of the sample holder at a distance of $10 \mathrm{~mm}$, and a magnetic field was applied around the sample holder. They concluded that the photocatalytic degradation of the dye depended on operational parameters such as the initial concentration of the dye, the settling duration, the type of photocatalyst, and the intensity of the applied magnetic field [36].

Sacco et al. [38] used white and blue LEDs as visible light irradiation sources for the photocatalytic degradation of methylene blue and methyl orange in aqueous solution. To accomplish this, they synthesized $\mathrm{N}$-doped $\mathrm{TiO}_{2}$ via the direct hydrolysis of titanium alkoxide with ammonia. Because of variations in ammonia doping, the bandgap of the titanium dioxide $\left(\mathrm{TiO}_{2}\right)$ ranged from 2.5 to $3.3 \mathrm{eV}$. Their photoreactor was equipped with a strip of 30 white light LEDs (wavelength of emission: 400-800 nm) with a nominal power of ca. $6 \mathrm{~W}$, or by a similar number of blue light LEDs (wavelength of emission: 400-550 $\mathrm{nm}$ ) with the same power as the white lights. The LED strip was covered on the outside of the reactor to ensure uniform light exposure of the reaction mixture. Their results showed that the highest photocatalytic degradation of methylene blue (7.5 $\mathrm{ppm}$ ) was obtained for photocatalysts with a bandgap of $2.6 \mathrm{eV}$. They also used the same set-up to mineralize methyl orange dye to confirm the catalyst's photocatalytic efficiency.

Natarajan et al. [39] developed a UV-LED and $\mathrm{TiO}_{2}$-coated quartz tube photocatalytic reactor. This reactor was successfully used for the mineralization of three dyes: methylene blue, malachite green, and Rhodamine B. Specifically, they coated the interior surface of the quartz tube with the P-25 Degussa photocatalyst after which the dye solution was passed through it, as shown in Fig. 4. The total amount of $\mathrm{TiO}_{2}$ deposited on the inside of the quartz tube was $2 \mathrm{mg}$. These tubes were then irradiated by 15 UV-LEDs (diameter: $5 \mathrm{~mm}$, wavelength: 390-410 $\mathrm{nm}$, optical rising time: $30 \mathrm{~ns}$ ). The radiant intensity of each LED was $350 \mathrm{mcd}$ and the radiant flux was around $12 \mathrm{~mW}$ at 20 mA.

Their study confirmed the photocatalytic mineralization of the dyes by UV-Vis spectroscopy, high pressure liquid chromatography (HPLC) and chemical oxygen demand (COD) analysis. Furthermore, they found that the success of the photocatalytic degradation of the dyes decreased as follows: malachite green $>$ Rhodamine $\mathrm{B}>$ methylene blue. They also investigated whether experimental parameters such as the flow rate of the solution through the coated tube reactor, the concentration of

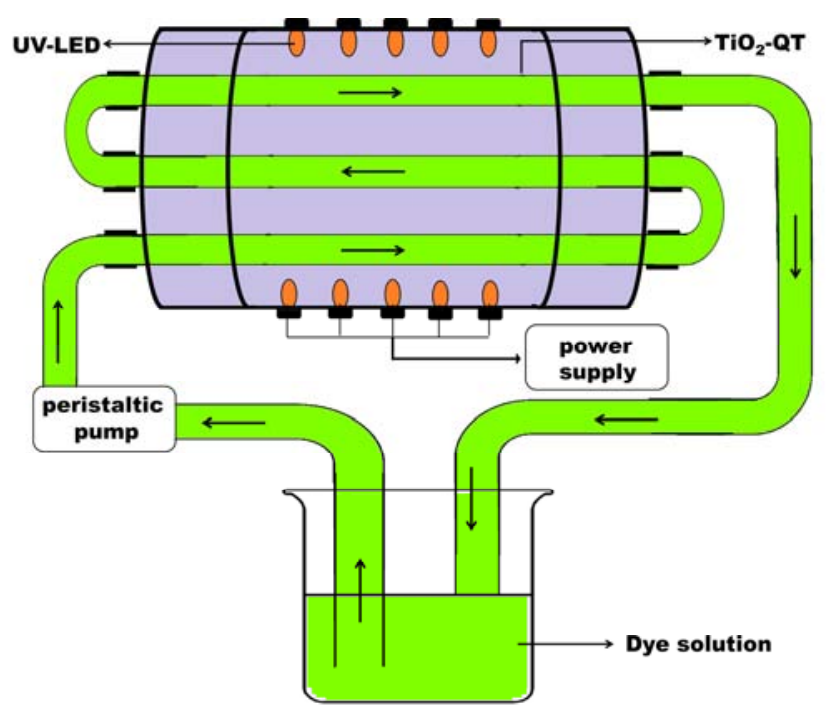

Fig. 4. Photocatalytic reactor using a $\mathrm{TiO}_{2}$ coated quartz tube and UV-LEDs.

the dye, and the $\mathrm{pH}$ influenced photocatalytic decomposition of the malachite green dye.

Based on a LC-MS analysis of the samples collected at different intervals during the photocatalytic degradation of malachite green (MG) they found that the decomposition of malachite green by the N-demethylation process leads to the creation of intermediates with a mass value of $m / z=315$, and that these $\mathrm{N}$-demethylated intermediates were further demethylated, giving mass values of 301, 287, 273, 259, 229, and 244 . Conversely, the addition of a hydroxyl group to malachite green upon reaction with hydroxyl radicals led to the formation of hydroxylated intermediates with $m / z=345$ and 361 that were demethylated giving mass values of 329,315 , and 298. Subsequently, the $\mathrm{N}$-demethylated intermediates were cleaved and oxidized by the formed hydroxyl radicals leading to the creation of intermediates with $m / z$ values of 229,214 , and 211 . These intermediates underwent further demethylation and oxidation yielding 2-(3,4-dihydroxyphenyl)-2-hydroxyacetic acid, benzaldehyde, benzenamine, nitrobenzene, phenol, and benzene. The generated oxidized intermediary products were then further converted into $\mathrm{CO}_{2}, \mathrm{NO}_{3}-\mathrm{NH}_{4}^{+}$, and $\mathrm{H}_{2} \mathrm{O}$. Overall, in this study they found that the photocatalytic surface of the $\mathrm{TiO}_{2}$ coated quartz tube was reusable and that the UV-LED photocatalytic mineralization of malachite green dye (and, by extension, other dyes) using this $\mathrm{TiO}_{2}$ coated tube system is economically viable and practical $[37,39]$.

Dai et al. [35,41,44] also used methylene blue as a test compound with a LED irradiation (wavelength: $450 \mathrm{~nm}$ ) set up and a plasmonic $\mathrm{Ag} / \mathrm{AgBr}$ heterostructure as the photocatalytic material. Specifically, they used a $5 \times 20$ LED array (Wuxi Chengtian Co., Ltd.) printed on a copper clad laminate as the light source, and a reaction vessel containing $100 \mathrm{~mL}$ of 10 $\mathrm{mg} / \mathrm{L}$ methylene blue and $0.05 \mathrm{~g}$ of the photocatalyst at room temperature. The distance between the LED light source and the reactor was $1 \mathrm{~cm}$, the light intensity that reached the reactor was $400 \mu \mathrm{W} / \mathrm{cm}^{2}$, and the reaction mixture was stirred continuously during the photocatalytic degradation. They 
found that using this system, 95\% methylene blue dye decomposition was observed over $240 \mathrm{~min}$ [35].

Repo et al. [34] synthesized CdS microspheres by a hydrothermal method for the photocatalytic decomposition of dyes upon exposure to near-UV and blue LED light irradiation. They investigated the decomposition of methylene blue, phenol red, and methyl red under irradiation by different LEDs (wavelengths: 405 and $450 \mathrm{~nm}$ ). The power consumption of the near-UV LED was $24 \mathrm{~W}$ and it was $17.5 \mathrm{~W}$ for the blue LED. Additionally, the radiation efficiency of the catalyst and dye-water mixtures were 1.2 and $3.2 \mathrm{~W}$ based on the intensity of the radiation ( 39 and $73 \mathrm{~mW} / \mathrm{cm}^{2}$ ) for a gap of $5 \mathrm{~cm}$ between the lamp and the solution, and a dye concentration of 3-5 $\mathrm{mg} / \mathrm{L}$. Under these conditions, a complete decolorization of the dye occurred within $3 \mathrm{~h}$.

Additionally, the photocatalytic activity of CdS microspheres with different size was investigated. The size of the microspheres was varied by applying different amounts of mercaptoethylamine hydrochloride (MEA) as a capping agent during their preparation. The photocatalytic decomposition of methylene blue dye in the presence of blue LEDs ( $3 \mathrm{~W}$ ) and solar light [43] was used as the model system. Specifically, the photocatalytic activity of the synthesized CdS photocatalysts with bandgaps of 2.34-3.10 eV was investigated. The smallest nanostructure had a bandgap of $2.74 \mathrm{eV}$ and the largest had a bandgap of $2.34 \mathrm{eV}$. Based on these results, they concluded that smaller nanostructures have enhanced photocatalytic efficiency because of an increase in the bandgap of the nanostructures and the resulting optimization of the redox potential of the nanostructures. Under exposure to blue LED light, the CdS photocatalyst exhibited higher photocatalytic decomposition activity than the commercial $\mathrm{TiO}_{2}$ photocatalyst (P25 Degussa). However, upon reusing the catalyst they found that after the first three cycles a gradual decrease in photocatalytic activity occurred, and after 5 cycles it was reduced to $50 \%$.

Dai et al. [35] developed a UV-LED/TiO 2 device for the degradation of methylene blue and it was composed of a UV-LED with an output wavelength of $376 \mathrm{~nm}$ as the UV light source. The device used in this study was composed of two open boxes made of polymethylmethacrylate (PMMA) with a thickness of 1 $\mathrm{mm}$. Four UV-LED light sources were put in the small box with lights on each side of the box. The small box was inserted into a bigger box, and the reaction medium was introduced into the space between them. The light source consisted of $6 \times 21$ UV-LED chip arrays printed on an Al substrate and it was powered by an external source. A total of $100 \mathrm{~mL}$ wastewater mixed with a $\mathrm{TiO}_{2}$ suspension was placed in the UV-LED/TiO device after which the UV-LED light power was adjusted using a direct current power supply. The properties of this UV-LED/ $\mathrm{TiO}_{2}$ device were investigated by varying the initial dye concentrations, the mass of the catalyst, the light power, and the $\mathrm{pH}$. They found that at initial dye concentrations of 5 , 10,20 , and $30 \mathrm{mg} / \mathrm{L}$ the rate constants were $1.002,0.406$, 0.269 , and $0.129 \mathrm{~h}^{-1}$, respectively. They also investigated the effect of light intensity and found that operating the UV-LED/ $\mathrm{TiO}_{2}$ device with a light power of $193.8 \mu \mathrm{W} / \mathrm{cm}^{2}$ was optimal for catalytic activity and energy efficiency.
It is always difficult to recover nanosized photocatalysts after photocatalytic experiments. Therefore, photocatalytic reactors have been developed using immobilized photocatalysts such as $\mathrm{TiO}_{2}$ deposited onto substrates, or titanium nanotubes grown on titanium metal plates. For example, a photocatalytic reactor based on a quartz cell fitted with a $\mathrm{TiO}_{2}$ nanotube array and containing UV-LEDs was used for the degradation of congo red [55]. In this reactor, a titanium nanotube array grown on the surface of a titanium metal plate $(30 \mathrm{~mm} \times 10 \mathrm{~mm})$ was placed at the center of the quartz cell and $5 \mathrm{ml}$ congo red dye solution was introduced to the cell. The quartz cell was irradiated using 4 UV-LEDs (2 LEDs on each of the two sides). The decomposition of congo red occurred on the titanium nanotube array surface. The experiments revealed that the initial rate of degradation of congo red was $0.77 \times 10^{-7} \mathrm{~mol} / \mathrm{L}$. The electrical energy per order $\left(E_{\mathrm{E} 0}\right)$, for low contaminant concentrations is defined as the number of $\mathrm{kW} h$ of electrical energy required to reduce the concentration of a pollutant by one order of magnitude $(90 \%)$ in $1 \mathrm{~m}^{-3}$ polluted water. The consumption of electrical energy $\left(E_{\mathrm{E} 0}\right)$ for the degradation of congo red dye was $228 \mathrm{~kW} \mathrm{~h} \mathrm{~m}^{-3}$ order-1 using a $\mathrm{TiO}_{2}$ nanotube array calcined at $450{ }^{\circ} \mathrm{C}$, while the initial rate of degradation under irradiation by UV light alone was $0.03 \times 10^{-7} \mathrm{~mol} / \mathrm{L}$ and the electrical energy was $14285 \mathrm{~kW} \mathrm{~h} \mathrm{~m}^{-3}$ order-1. $^{-1}$ The developed photocatalytic surface had good reusability, and the degradation of congo red was found to decrease by only $5 \%$ after five uses. A degradation pathway was proposed by Natarajan et al. [55] and is given in Scheme 2.

A batch reactor containing UV-LEDs and potassium peroxydisulfate $\left(\mathrm{K}_{2} \mathrm{~S}_{2} \mathrm{O}_{8}\right)$ with a LED cooling array was investigated for the degradation of reactive black 5 . The working volume of the reactor was $100 \mathrm{~mL}$ and the peroxydisulfate concentration was varied (10-200 $\mathrm{mmol} / \mathrm{L})$, as was the dye concentration (5-40 $\mathrm{ppm})$. The effect of $\mathrm{pH}$ was also studied from $\mathrm{pH}=2$ to $\mathrm{pH}=10$. Six UV-LEDs ( $1 \mathrm{~W}$ ) were used to carry out the photocatalytic experiments. In a beaker, the dye solution and $\mathrm{K}_{2} \mathrm{~S}_{2} \mathrm{O}_{8}$ were stirred under the LEDs at a constant temperature of $25^{\circ} \mathrm{C}$. The effects of different UV-LED exposures and applied currents were also investigated. Based on the power consumption of the system, the electrical energy per order for the degradation of reactive black 5 was calculated for both traditional UV lamps and LEDs [54].

A closed water circuit with an integrated real-time, in-stream sensor was designed by Nickels et al. [50]. The reactor comprises a reactor vessel with inlets and outlets as well as a glass chamber (84 $\mathrm{mm}$ inner diameter and $70 \mathrm{~mm}$ height) and a base coated with photocatalytic material (Evonik $\mathrm{TiO}_{2}$ Aeroxide P25). 15 UV-LEDs were mounted on the reactor cover and the photocatalyst coated surface was attached to the reactor base at a distance of $65 \mathrm{~mm}$ from the UV-LEDs. Ultra Bright Deep Violet LED370E UV-LEDs were used as the UV light irradiation source to promote the photocatalytic degradation of methyl orange [50]. The inlets and outlets were $4 \mathrm{~mm}$ diameter glass tubes located $10 \mathrm{~mm}$ from the bottom of the reactor, which was filled with the test liquid in volumes ranging from 100 to $250 \mathrm{~mL}$. A centrifugal pump was used to mix the solution and circulate water in the reactor. The photocatalytic de- 


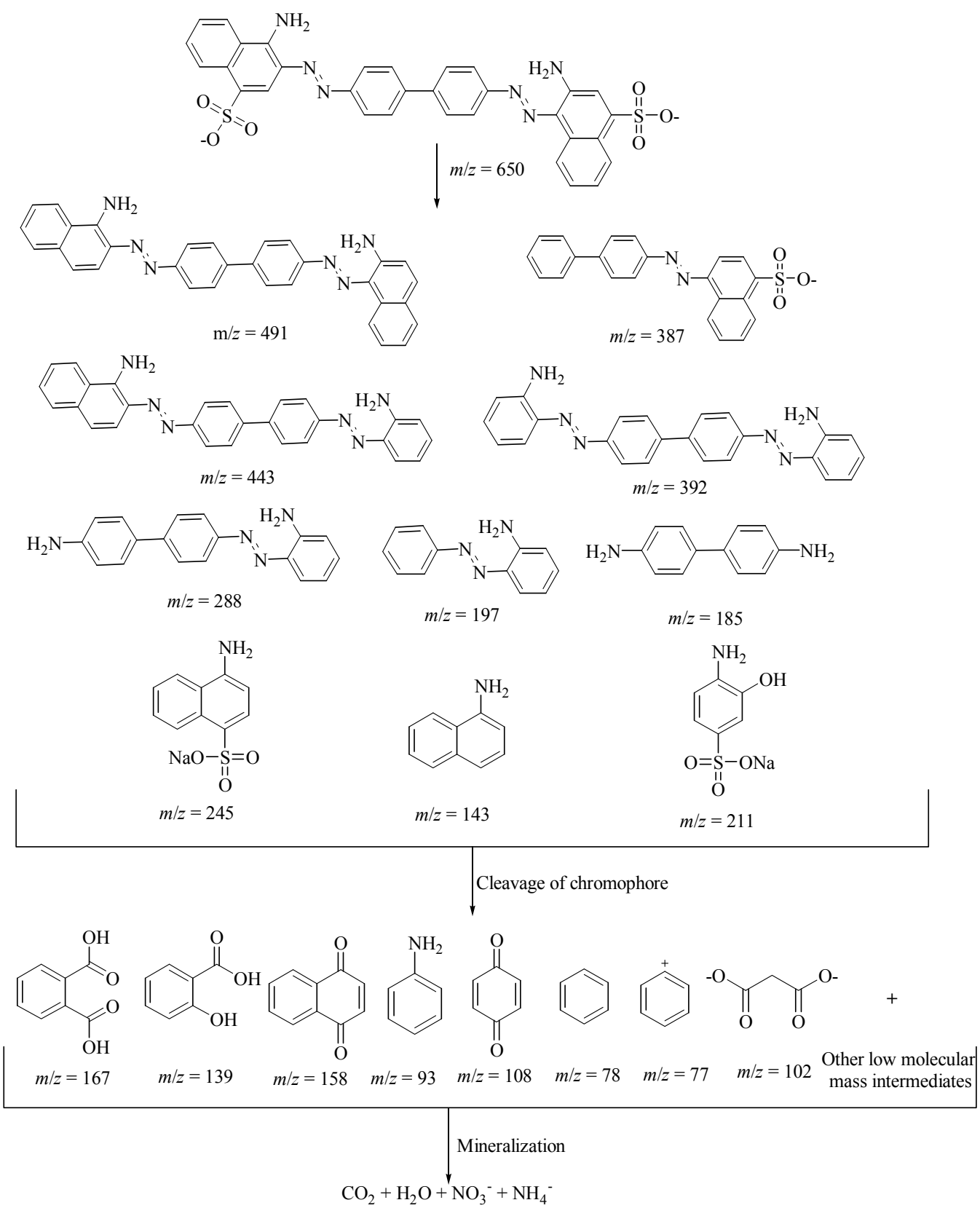

Scheme 2. Proposed photocatalytic degradation pathway for congo red upon UV-LED exposure.

composition of methyl orange was investigated by a series of experiments in which the initial concentration of the dye, the irradiance, and the liquid volume were varied.

An annular-type photocatalytic reactor was developed by Tokode et al. [51] to investigate the photocatalytic decomposition of methyl orange $\left(2.5 \times 10^{-5} \mathrm{~mol} / \mathrm{L}\right)$ under controlled periodic illumination with UV-LEDs to enhance the photonic efficiency of photocatalytic decomposition in water. An array of LEDs (LED sources: FoxUV ${ }^{\mathrm{TM}}, 5 \mathrm{~mm}$ diameter with a peak wavelength of $360 \mathrm{~nm}$, a viewing angle of $15^{\circ}$, and an average radiant power of $435 \mu \mathrm{W}$ in strips) was used for irradiation and the outer chamber was coated with a reflective aluminum film to minimize photonic loss from the reactor. This study showed an increase in photonic efficiency with a reduction in the duty cycle that depended on the duty cycle time rather than light or dark time periods suggesting that the reaction is not limited by mass diffusion or by adsorption/desorption to and from the $\mathrm{TiO}_{2}$ powder surface. Moreover, the photonic efficiency of the CPI increased with a decrease in power levels under lower UV-power densities. For the photoreactor used in this study (with lower power densities), the photonic efficiency from controlled periodic illumination followed the same trend as that under continuous illumination indicating a non-limited carrier recombination process.

Loetscher et al. [40] developed a titania-acrylic coil reactor for the degradation of methyl orange and methylene blue. A lightweight, economic, portable reactor was fabricated using a coating of $\mathrm{TiO}_{2}$ on a UV-transparent acrylic sheet. They demon- 
strated that pollutants including dyes like methyl orange, methylene blue, as well as lead and bacteria could be removed using this photocatalytic reactor under illumination by LEDs and compact fluorescent backlights (CFL). Furthermore, they reported that the photocatalytic efficiency of the reactor was unchanged for $1100 \mathrm{~h}$ and that the removal and/or degradation of these pollutants proceeded without change over the time scale of the experiment.

The photocatalytic decomposition of dyes was also investigated using catalysts other than titanium oxide under UV-LED irradiation. Sun et al. [56] synthesized laminar structured $\mathrm{Bi}_{2} \mathrm{MoO}_{6}$ with a $2.52 \mathrm{eV}$ bandgap energy by the hydrothermal method. They then conducted experiments in a dispersion medium using $0.05 \mathrm{~g}$ of the photocatalyst and $50 \mathrm{~mL}$ Rhodamine $\mathrm{B}$ solution $(0.1 \mu \mathrm{mol} / \mathrm{L})$ under blue LED irradiation with continuous magnetic stirring. The results of their experiments suggest that electrons and holes play an important role in the degradation of Rhodamine $\mathrm{B}$ with holes playing the most important role.

Rhodamine B dye degradation under UV-LED irradiation was also reported in a system employing a polymer modified ZnO photocatalyst using a column glass reactor [58]. Specifically, they used three $1 \mathrm{~W}$ LEDs (radiant wavelength: 450-475 $\mathrm{nm}$ ) located firmly against the reactor spaced $120^{\circ}$ from each other as a visible light source. The photocatalytic reactor was kept open to air to allow sufficient oxygen to access the reaction solution. Around 40\% phenol and methyl orange decomposition was achieved using this set-up after $2 \mathrm{~h}$ of irradiation. $\mathrm{RhB}$ was completely degraded within the same irradiation time [58].

\section{Future prospects of LEDs}

Recent developments in solid-state semiconductor technology have provided a variety of LEDs useful for general lighting as well as more specific application resulting in increased production and, therefore, decreased cost. The advantages of LEDs are that no cooling is required, they are small, and are useful in different types of photocatalytic reactor set-ups. Furthermore, LED irradiation is unidirectional and thus, an appropriately designed reactor will not leak UV light and can achieve high photocatalytic efficiency. Because of this unidirectional irradiation the loss of light is lower than that of traditional UV light lamps. Reactors employing traditional UV irradiation sources can waste up to $80 \%$ of the light that they produce. Conversely, LEDs emit specific wavelengths of light that are completely used. As there are many advantages over conventional traditional UV sources, many researchers have focused on the development of photocatalytic reactors based on LEDs and the synthesis of photocatalysts that can provide high photocatalytic activity in these systems. To develop a photocatalytic reactor with the optimum photocatalytic efficiency, it is necessary to select appropriate LEDs and design appropriate reactors. However, this is a challenging task. Additionally, LEDs can be operated at low voltage, enabling them to be powered using solar photovoltaic panels. Studies have shown that for certain application, replacing mercury lamps with UV-LEDs can lead to a reduction in $\mathrm{CO}_{2}$ production of 25 tons.

Overall, the available literature indicates that LEDs can play a major role in the future development of photocatalytic processes for environmental pollution abatement, and can enable the development of photocatalytic reactors with high throughput that are environmentally friendly, energy-efficient, and compact. UV-LEDs are also useful for the development of microreactors, which can exhibit improved properties such as higher lighting homogeneity and penetration compared with large-scale reactors. However, further progress in the development of high-power UV-LEDs is needed to produce reliable, energy-efficient, and small photocatalytic reactors. Such advances will help meet the increasing demand for the implementation of clean energy technology.

\section{Conclusions}

Over the last two to three decades, extensive research has been conducted into the use of photocatalysis for the removal of dyes from wastewater. These studies have dealt with the synthesis of new photocatalysts with higher surface areas, different morphology, different phase structure, and varying composition of metals and non-metals. These tests have primarily been conducted using UV lamps or other methods to promote the photocatalytic decomposition of dyes upon exposure to solar light. However, the use of traditional UV light sources is problematic because they require cooling strategy, have high-energy costs, and can be harmful. Systems employing sunlight have high initial installation costs and require the regular tracking of sunlight. Moreover, the rate of degradation using sunlight is lower than that for irradiation by conventional UV sources. Consequently, researchers have been investigating alternative light sources such as LEDs for the photocatalytic decomposition of various organic compounds and dyes. However, to date, few dyes have been photocatalytically degraded under irradiation by LEDs at low concentrations. Accordingly, there is a need to investigate different dyes to confirm the photocatalytic decomposition of each dye upon exposure to LED irradiation. Both UV and visible LEDs are available, and appropriate photocatalysts may help achieve higher levels of photocatalytic degradation. Currently, investigations into UV-LEDs as an alternative source of UV light are generally conducted using standard P25 Degussa photocatalysts. However, some effort has been made to modify P25 Degussa, and the synthesis of other photocatalysts such as $\mathrm{CdS}$ and $\mathrm{Bi}_{2} \mathrm{MoO}_{6}$ has been conducted.

Based on the available literature, it is clear that an increase in the number and power of available LEDs will allow researchers to attain better photocatalytic degradation of dyes in shorter reaction time. Moreover, the studies conducted have shown that visible LEDs can also be used for the photocatalytic decomposition of various dyes by employing photocatalysts with a bandgap in the range of $2.0-3.1 \mathrm{eV}$.

Overall, the available literature indicates the feasibility of UV and visible LEDs for the photocatalytic decolorization and mineralization of dyes in water. Moreover, they can be useful for the removal of other pollutants present in water and air. Inves- 
tigations into LED illumination for the degradation of dyes have indicated that they are effective when applied to low concentrations of dyes, but their intensity will need to be increased to enable their application to industrial effluent. Additionally, these emerging techniques must be evaluated using a variety of pollutants to validate the use of LEDs in the photocatalytic treatment of dye contaminated wastewater.

\section{Acknowledgments}

This study was conducted with the support of the MSIP (Ministry of Science, ICT \& Future Planning, Project No. 132S-5-3-0610) and the National Research Foundation of Korea (NRF) funded by the Korean Government (MEST, No. 2011-0027916). One of the authors (RJT) also thanks Mr. Sivakumar Thillai, Dr. S. Shin and Mr. Joon Y. Lee for their help with the literature search.

\section{References}

[1] Gaya U I, Abdullah A H.J Photochem Photobiol C, 2008, 9: 1

[2] Lazar M A, Varghese S, Nair S S. Catalysts, 2012, 2: 572

[3] Forgacs E, Cserhati T, Oros G. Environ Int, 2004, 30: 953

[4] Galinado C, Jacques P, Kalt A. Chemosphere, 2001, 45: 997

[5] Vautier M, Guillard C, Herrmann J M. J Catal, 2001, 201: 46

[6] Priyaragini S, Veena S, Swetha D, Karthik L, Kumar G, Bhaskara Rao K V.J Environ Sci, 2014, 26: 775

[7] Pan H M, Feng J H, He G X, Cerniglia C E, Chen H Z. Anaerobe, 2012, 18: 445

[8] McKay G. Am Dyes Rep, 1979, 68(4): 29

[9] Chang M W, Chung C C, Chern J M, Chen T S. Chem Eng Sci, 2010, 65: 135

[10] Tang W Z, An H. Chemosphere, 1995, 31: 4157

[11] Chakrabarti S, Dutta B K. J Hazard Mater, 2004, 112: 269

[12] Rao A N, Sivasankar B, Sadasivam V. J Mol Catal A, 2009, 306: 77

[13] Sobana N, Swaminathan M. Sol Energ Mater Sol Cells, 2007, 91: 727

[14] Aleboyeh A, Kasiri M B, Aleboyeh H. J Environ Manage, 2012, 113: 426

[15] Huang H B, Leung D Y C, Kwong P C W, Xiong J, Zhang L. Catal Today, 2013, 201: 189

[16] Surolia P K, Lazar M A, Tayade R J, Jasra R V. Ind Eng Chem Res,
2008, 47: 5847

[17] Lazar M A, Tayade R J, Bajaj H C, Jasra R V. Nano Hybids, 2012, 1: 57

[18] Chen H W, Ku Y, Wu C Y. J Chem Technol Biotechnol, 2007, 82: 626

[19] Daniel D, Gutz I G R. Electrochem Commun, 2007, 9: 522

[20] Jo W K, Eun S S, Shin S H. Photochem Photobiol, 2011, 87: 1016

[21] Jo W K. Materials, 2013, 6: 265

[22] Jo W K, Tayade R J. Ind Eng Chem Res, 2014, 53: 2073

[23] Dutta G S, Jatothu B. Plant Biotechnol Rep, 2013, 7: 211

[24] Rauf M A, Ashraf S S. Chem Eng J, 2009, 151:10

[25] Tayade R J, Suroliya P K, Kularani R G, Jasra R V. Sci Technol Adv Mater, 2007, 8: 455

[26] Mills A, Lee S K.J Photochem Photobiol A, 2002, 152: 233

[27] Lee S K, Mills A.J Ind Eng Chem, 2004, 10: 173

[28] Chakrabarti S, Dutta B K. J Hazard Mater, 2004, 112:269

[29] Maldotti A, Molinari A, Amadelli R. Chem Rev, 2002, 102: 3811

[30] Shiraishi Y, Hirai T.J Photochem Photobiol C, 2008, 9: 157

[31] Tayade R J, Natarajan T S, Bajaj H C. Ind Eng Chem Res, 2009, 48: 10262

[32] Chen D H, Ye X J, Li K Y. Chem Eng Technol, 2005, 28: 95

[33] Autin O, Romelot C, Rust L, Hart J, Jarvis P, MacAdam J, Parsons S A, Jeffersopn B. Chemosphere, 2013, 92: 745

[34] Repo E, Rengaraj S, Pulkka S, Castangnoli E, Suihkonen S, Sopanen M, Sillanpää M. Sep Purif Technol, 2013, 120: 206

[35] Dai K, Lu L H, Dawson G. J Mater Eng Perform, 2013, 22: 1035

[36] Joonwichien S, Yamasue E, Okumura H, Ishihara K. J Chem Chem Eng, 2011, 5: 729

[37] Thillai S N, Natarajan K, Bajaj H C, Tayade R J. In: Inamuddin Ed. Advanced Functional Polymers and Composites: Materials, Devices and Allied Applications. Nova Science Publishers, USA, 2013. 33

[38] Sacco O, Stoller M, Vaiano V, Ciambelli P, Chianese A, Sannino D. Int J Photoenergy, 2012, 2012: Article ID 626759

[39] Natarajan K, Thillai S N, Bajaj H C, Tayade R J. Chem Eng J, 2011, 178: 40

[40] Loetscher L H, Carey J M, Skiles S L, Carey V M, Boyd J E. Ind Eng Chem Res, 2009, 48: 4697

[41] Dai K, Lu L H, Zhu G P, Liu Z L, Liu Q Z, Chen Z. Mater Lett, 2012, 87: 94

[42] Stefanov B I, Kaneva N V, Puma L I, Dushkin C D. Colloids Surf A, 2011, 382: 219

[43] Eskandari P, Kazemi F, Azizian-Kalandaragh Y. Sep Purif Technol, 2013, 120: 180

[44] Dai K, Lü J L, Lu L H, Liu Q, Zhu G P, Li D P. Mater Lett, 2014, 130: 5

\section{Graphical Abstract}

Chin. J. Catal., 2014, 35: 1781-1792 doi: 10.1016/S1872-2067(14)60205-9

Recent developments in photocatalytic dye degradation under irradiation with energy-efficient light emitting diodes

Wan-Kuen Jo, Rajesh J. Tayade*

Kyungpook National University, Korea;

CSIR-Central Salt and Marine Chemicals Research Institute, India

This review focuses on photocatalytic dye degradation by energy-efficient light emitting diodes and summarizes recent developments in photocatalytic reactors, photocatalysts, and the degradation mechanism of irradiation upon using various light emitting diodes.

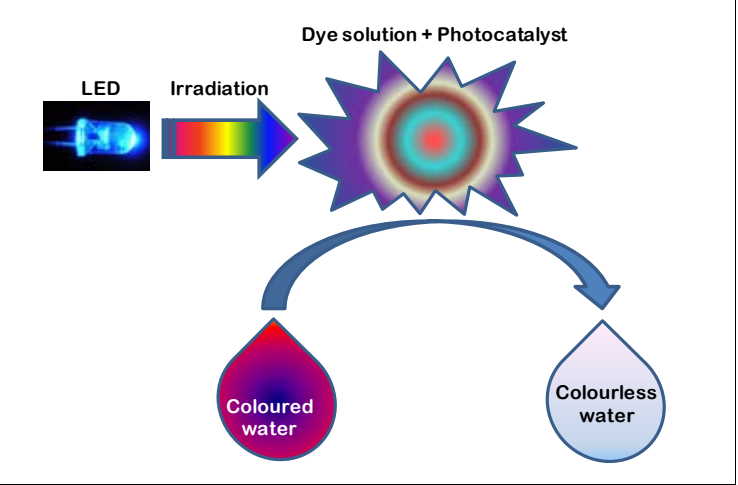


[45] Dai K, Lu L H, Liang C H, Dai J M, Zhu G P, Liu Z L, Liu Q Z, Zhang Y X. Mater Chem Phys, 2014, 143: 1410

[46] Rasoulifard M H, Marandi M R, Majidzadeh H, Bagheri I. Environ Eng Sci, 2011, 28: 229

[47] Natarajan T S, Thomas M, Natarajan K, Bajaj H C, Tayade R J. Chem Eng J, 2011, 169: 126

[48] Rasoulifard M, Fazli M, Eskandarian M. J Ind Engg Chem, 2014, 20: 3695

[49] Wang W Y, Ku Y. Water Res, 2006, 40: 2249

[50] Nickels H, Zhou H, Basahel S N, Obaid A Y, Ali T T, Al-Ghamdi A A, El-Mossalamy E S H, Alyoubi A O, Lynch S A. Ind Eng Chem Res, 2012, 51: 3301

[51] Tokode O I, Prabhu R, Lawton L A, Robertson P K J. J Catal, 2012, 290: 138
[52] Shoaebargh S, Karimi A, Dehghan G. J Taiwan Inst Chem Eng, 2014, 45: 1677

[53] Kuo Y L, Su T L, Kung F C, Wu T J. J Hazard Mater, 2011, 190: 938

[54] Rasoulifard M H, Zarei M. International Conference on Agriculture, Chemical and Environmental Sciences (ICACES'2012). Dubai (UAE), 2012

[55] Natarajan T S, Natarajan K, Bajaj H C, Tayade R J. Ind Eng Chem Res, 2011, 50: 7753

[56] Sun Y Y, Wang W Z, Zhang L, Sun S M. Mater Res Bull, 2013, 48: 4357

[57] He G H, Liang C J, Ou Y D, Liu D N, Fang Y P, Xu Y H. Mater Res Bull, 2013, 48: 2244

[58] Qiu R, Zhang D D, Mo Y Q, Song L, Brewer E, Huang X F, Xiong Y.J Hazard Mater, 2008, 156: 80 